\title{
Despite Resemblance - Scale Models and the Representation of Architectural Objects
}

\author{
By João Miguel Couto Duarte*
}

The challenge of exploring 'Inter and Transdisciplinary Relationships in Architecture' might be embraced as a possibility to outward as much as to inward the comprehension of architecture and its design. This paper aims to reconsider the relationship between scale models and architectural objects after Nelson Goodman's discussion about resemblance and representation in 'Languages of Art', thus allowing a new understanding of the role of architectural representation in architectural design. In 'Languages of Art' the still common belief that representation profits from some sort of resemblance to its object is deemed untenable. It is strictly arbitrary the relation between one and the other. That is why - Goodman remarks - "almost anything may stand for almost anything else." Drawings and photography might confirm Goodman's statement since only a convention seems to allow the recognition of a three-dimensional object in a bidimensional one. But that is not the case with scale models. Due to its nature it remains comfortable to think about a scale model as having a natural resemblance to an architectural object, thus seeming its closest representation. Nevertheless Goodman's proposals must be considered. Also scale models must be scrutinized as strictly arbitrary representations, resting upon a system of conventions instead of a set of proprieties shared with the architectural object it is meant to replace. And being confirmed its strictly arbitrariness, that is, being confirmed that is devoid of any natural relation with its subject, scale model's role in architectural design must also be scrutinized. This paper will first discuss scale models' representational nature and, subsequently, how the radical difference it holds from the object thus represented matters to architectural design. Scale models ought to be comprehended despite the resemblance deluded with the architecture they allow to envision.

\section{Initial Considerations}

\begin{abstract}
"The deceptively convincing nature of models can easily mislead one into ignoring their essentially fictitious representational character as well as their inherent high degree of abstraction."
\end{abstract}

Alongside other systems of representation, scale models are still trusted by architects to invent the world.

Scale models are singular representations. Being singular because of all forms

\footnotetext{
*Assistant Professor/Research Fellow, Lusíada University/CITAD, Portugal.

1. C. Gänshirt, Tools for Ideas an Introduction to Architectural Design (Basel Boston Berlin: Birkhäuser Verlag AG, 2007), 153.
} 
of representation at the architect's disposal scale models seem to be the closest to architectural objects. As the architectural objects, scale models have a threedimensional existence and are the outcome of a building like process. Between one and the other there seems to be a natural resemblance, sometimes enhanced by the fact that a scale model might stand as a quasi-architectural object. Large sized walk-in scale models confirm it.

But scale models are also singular representations because it still remains largely unacknowledged the nature of the links that allow them a relation with architectural objects. Apparently those links are warrant because scale models reproduce some of the proprieties held by the architectural object they are meant to replace, by virtue of sharing with those objects the aforementioned threedimensional existence. Hence the natural resemblance that seems to exist between them and the common classification of a scale model as an iconic model. ${ }^{2}$ But that seeming capacity of reproducing proprieties cannot hide the differences that will always stand between a scale model and an architectural object, even because there is more than just an algebraic operation involved in the scalar conversions usually required by a model. And a scale model differs from the architectural object it represents by size, by shape, by material, by structural behaviour. Nevertheless, that distinction is more than just a constraint since it proves necessary to establish representation. Only being distinct from its object enables a scale model to replace and represent an architectural object. If a scale model reproduced an architectural object in all its complexity and completeness it would be that object and not a representation of it. But the extent and the consequences of that difference are still unclear.

The relation between a scale model and an architectural object thus convokes an inquiry. Alongside a seeming natural resemblance, or perhaps rather than it, it must be considered the possibility of that relation relaying, at least partially, if not totally, in a set of artificial links, maybe even arbitrary ones, in a system of conventions that allows one object to be taken as another object, thus becoming a scale model of an architectural object. But another inquiry is convoked. Being confirmed that the relation between a scale model and an architectural object relies strictly upon a system of conventions instead of a seeming resemblance, and being confirmed that are strictly arbitrary the links bounding one to the other, the difference standing between a scale model and an architectural object turns out radical, ruling out any propriety sharing with architectural objects by which scale

2. "With the physical model, the physical characteristics of reality are represented by the same or analogous characteristics in the model. It can be divided into two categories: [...] [t]he first is called 'iconic', in which 'the physical properties are represented only by a change of scale' R. Ackoff, S. Gupta and J. Minas, Scientific Method. Optimizing applied research decisions [New York \& London: John Wiley \& Sons, 1962]. This class includes architectural models, photographs, etc. [...] The second is called 'analogue', and here 'the physical properties of the real world are represented by different proprieties.' C. Churchman, R. Ackoff and E. Arnoff, Introduction to Operations Research [New York \& London: John Wiley \& Sons, 1957]. This class includes maps, plans, graphs, etc." M. Echenique, "Models: a discussion," in Urban space and structures (ed.) L. Martin and L. March (Cambridge: Cambridge University Press, 1975), 172. Echenique paraphrases Ackoff, Gupta and Minas, Scientific Method. Optimizing applied research decisions, 1962, 109 and Churchman, Ackoff and Arnoff, Introduction to Operations Research, 1957, 158. 
models are still enjoyed. The role of scale models in architectural design must therefore be revaluated.

Scale models' enchantment must be overcome.

\section{Representation, after Goodman}

\section{Resemblance Reconsidered}

The scope of this reflection must now be enlarged in order to cover representation on a wider meaning.

Representation is addressed by Nelson Goodman in 'Languages of Art.', Goodman states his goal as "an approach to a general theory of symbols," being 'symbol' used "as a very general and colorless term. It covers letters, words, texts, pictures, diagrams, maps, models, and more, but carries no implication of the oblique or the occult. The most literal portrait and the most prosaic passage are as much symbols, and as 'highly symbolic', as most fanciful and figurative.",

The importance of resemblance to explain representation is dismissed by Goodman at the very beginning of his exposition. Goodman points out the feebleness of how representation is commonly approached. Resemblance fell short to explain representation. "The most naïve view of representation might perhaps be put somewhat like this: " $A$ represents $B$ if and only if $A$ appreciably resembles $B$ ", or " $A$ represents $B$ to the extent that $A$ resembles $B . " 6$ The faults of this view are exposed by Goodman as 'obvious enough'. "An object resembles itself to the maximum degree but rarely represents itself; resemblance, unlike representation, is reflexive. Again, unlike representation, resemblance is symmetric: $B$ is as much like $A$ as $A$ is like $B$, but while a painting may represent the Duke of Wellington, the Duke doesn't represent the painting. Furthermore, in many cases neither one of a pair of very like objects represents the other: none of the automobiles off an assembly line is a picture of any of the rest; and a man is not normally a representation of another man, even his twin brother."7 So, Goodman concludes: "[p]lainly, resemblance in any degree is no sufficient condition for representation." And if it is still insisted upon, resemblance should better be sought between representations, not between a representation and the object its stand for. "A Constable painting of Marlborough Castle is more like any other picture than it is the Castle, yet it represents the Castle and not another picture - not even the closest copy."

Goodman reconsiders representation. For an object to represent another object it must 'be a symbol for it', it must 'stand for it', it must 'refer to it'. Resemblance

3. N. Goodman, Languages of Art: an approach to a theory of symbols (Indianapolis/ Cambridge: Hackett Publishing Company, Inc., 1976).

4. Ibid, xi.

5. Ibid, xi.

6. Ibid, 3 .

7. Ibid, 4.

8. Ibid, 4.

9. Ibid, 5. 
is thus proved not only insufficient but also dispensable to representation. Resemblance is no condition for a reference to. After all, Goodman remarks, "almost anything may stand for almost anything else." refer to the object it stands for, denotation turns out key to representation. And if denotation turns out key to representation, the limits between a pictorial representation of an object - or an architectural scale model of it, one might consider - and a verbal description of the same object blur. In both cases, an object is referred to by another object. Despite the differences that are still possible to identify between them, a picture emerges as much as the result of a system of conventions as a verbal description does. Arbitrariness is unveiled as permeating representation - arbitrariness not because representation is the outcome of a discretionary will from its author, but because it is devoid of any natural relation with the object being referred to. Things are not recognizable due to resemblance; things are recognized as being resembling.

Representation might be understood as an encounter between two distinct objects: the one that refers to and the one being referred to, which may or may not be an extant one. Proprieties pertaining to the former are recognized as proprieties pertaining to the latter. But no propriety transfer should be sought in this process, since pertaining to objects proprieties are not transferable. And no propriety reproduction should be sought either. It is a coded equivalence of proprieties that is to be considered here. "A perceptual equivalence is established between representation and represented through which representation evokes the proprieties belonging to the thing being represented as if it were there, not being in fact."11 One must nevertheless acknowledge that this is neither a direct, nor a guaranteed process. Because it rests upon the existence of a system of codes by which meaning is established, representation requires an interpretation, thus being dependent on each person's observation - on his memories, on his context, on his expectations. "Nothing is seen nakedly or naked." 12 And one must also acknowledge that this is not a self-enclosed process. Because it is framed within a given cultural context, each representation is backgrounded by the standard systems of representation existing on that context - which are predominantly 'realistic' on western culture - and evaluated according to those systems' current validation criteria - which are based on resemblance on 'realistic' systems.

Goodman draws the meaning of resemblance in representation after questioning the meaning of realism. "Realism is relative, determined by the system of representation standard for a given culture or person at a given time."13 That is why 'realistic representations' throughout history look so different from one another. Realism must be thought based on expectations, and it must not be confused with correctness, the latter being determined by how rigorous the information about the object represented is according to the rules of the

10. Ibid, 5 .

11. Translated by the author. Original text: "estabelece uma equivalência perceptiva entre representação e representado através da qual a representação evoca as propriedades da coisa representada como se ela lá estivesse, não estando de facto." P. Janeiro, Origens e Destino da Imagem: para uma fenomenologia da arquitectura imaginada (Lisboa: Chiado Editora, 2010), 218.

12. Goodman, Languages of Art: an approach to a theory of symbols, 1976, 8.

13. Ibid, 37. 
representational system taken, and the former being determined by how coincident that system is with the current standard one. "Realistic representation, in brief, depends not upon imitation or illusion or information but upon inculcation. [...] If representation is a matter of choice and correctness a matter of information, realism is a matter of habit." There rests the key to understand resemblance. The recognition of a resemblance denotes not only an equivalence between proprieties pertaining to a representation and proprieties pertaining to the object it refers to, but also the permanence of the models and the systems of representation underneath that recognition.

No longer is about verifying that a picture representing nature is more like any other picture then nature itself - that was the meaning of Goodman's remark about a supposed Constable painting of Marlborough Castle; rather, "That a picture looks like nature often means that it looks the way nature is usually painted."15

Resemblance is a result of representation, not a condition to accomplish it.

\section{'A Theory of Notation'}

As aforementioned Goodman stated his goal for 'Languages of Art' as "an approach to a general theory of symbols," 16 being 'symbol' used "as a very general and colorless term."17

Goodman constructs his theory from the notion of 'reference' - as much as 'symbol', 'reference' is taken as a very general term. 'Referring to' is the condition that allows something to be a symbol for something else. Something may 'stand for' something else if it 'refers to it'. And, one must remember Goodman's remarks, "almost anything may stand for almost anything else."18 Reference underlies all forms of symbolizing.

This is Goodman's departure point, from which his inquiry might be foreseen, as pinpointed by Capdevila-Werning. "This primitive relation constitutes the keystone of the theory and as such cannot be defined by any external notion, but is rather elucidated by the different modes in which reference takes place."19 Goodman is focused on systems of symbols rather than on kinds of symbols. How a symbol means must not be confused with what a symbols means. And a symbols means only within a symbol system. No symbol has a meaning by itself, and no meaning resists outside the symbols system within which it was perceived. "The modes of reference are how a symbol means; what a symbol means is determined by the symbol system." ${ }^{20}$ Goodman's theory undertakes a unified approach to both linguistic and non-linguistic systems of symbols, used as much in art as in sciences and in everyday life. There lays Goodman's understanding of arbitrariness.

Considering that "[a]ny symbol scheme consists of characters, usually with

14. Ibid, 38 .

15. Goodman, Languages of Art: an approach to a theory of symbols, 1976, 39.

16. Ibid, xi.

17. Ibid, xi.

18. Ibid, 5.

19. R. Capdevila-Werning, Goodman for architects (London and New York: Routledge, 2014), 32 .

20. Ibid, 32 . 
modes of combining them to form others," ${ }^{21}$ a system of symbols consists of "a symbol scheme correlated with a field of reference.",22 Each character comprehends all marks - visual, auditory, etc. - that have a correspondence with it, being that correspondence determined by the rules of the scheme. A letter from the Latin alphabet, for instance, comprehends all its oral expressions and all its graphic inscriptions. Symbols schemes are organized according to syntactic rules; symbol systems of are organized according to semantic rules. Symbol systems differ among each other due to their semantic and syntactic features. "Depending on whether these features are more or less strict, one can classify the kinds of systems in a continuum that ranges from differentiated or attenuated to nondifferentiated or dense systems." 23

Goodman distinguishes the different kinds of symbol systems departing from notational systems, for being the ones with the strictest correlation between symbol schemes and fields of reference. "Notations [...] can be placed at the differentiated end of the variety of symbol systems." 24 A score is a notational system. "Not only must a score uniquely determine the class of performances belonging to the work, but the score (as a class of copies or inscriptions that so define the work) must be uniquely determined, given a performance and the notational system." 25

A notational scheme is therefore marked by a 'character-indifference', and each character has to be 'finitely differentiable' or 'articulated'. The Latin alphabet is an example of a notational scheme: as characters, letters are indifferent to the variations of their marks, since the graphic forms ' $\mathrm{A}$ ', ' $\mathbf{a}$ ' or ' $a$ ', for example, do not compromise the recognition of the character ' $a$ ', they are not mistaken with the letter ' $b$ ', for example, being possible to differentiate which marks might be articulated with which character. ${ }^{26}$ If between two characters exists a third one, a scheme will be 'dense'. A continuous colour gradation, for instance, is a dense scheme since it is always possible to find a hue between two others hues.

A notational system has to be 'unambiguous', 'disjoint' and have a 'finite differentiation'. This means that each character can only be conform with a class of elements belonging to the reference field, the compliance classes thus established cannot overlap each other, not even partially, and it has always to be possible to identify which symbol is in conformity to which element from a reference field. If in a continuous array of characters it is not possible to identify that an element from a reference field is not in conformity to no one of those characters, the system to which pertains that array will be semantically dense. A ruler, for example, will be a partially dense system if its minimal measuring unity is larger than the minimal unity that needs to be measured, for the exact length of some dimensions will not be possible to determine. The problem will be solved if both measures coincide with each other, thus turning the system a finitely

21. Goodman, Languages of Art: an approach to a theory of symbols, 1976, 131.

22. Ibid, 143.

23. Capdevila-Werning, Goodman for architects, 2014, 33.

24. Ibid, 33.

25. Goodman, Languages of Art: an approach to a theory of symbols, 1976, 129-130.

26. "Sometimes 1 can be mistaken by the lower case letter 1 ; hence, this aspect of notations is only valid in theory and not in practice." Capdevila-Werning, Goodman for architects, 2014, 33. 
differentiated one once again.

But neither the differentiation nor the density of a symbol scheme implicates that the symbol systems to which that symbol scheme pertains necessarily has to be either differentiated or dense. Verbal languages, for example, even if being syntactically differentiated, are semantically dense, because their compliance classes might be ambiguous. Poetry, being its plural meaningfulness acknowledged, confirms it. And not all symbol systems are based on differentiated schemes, thus resulting their density. The elements forming a drawing - its lines and its washes - are continuously and indefinitely varied, as testified by a sketch in painting or an architectural study drawing.

The recognition of the density and the lack of articulation of non-linguistic systems must not be understood as a devaluation of those systems over linguistic ones, as if the former were less capable than the latter to convey a meaning. Rather it must be understood as a concomitant comprehension of the different systems, revealing the relativity permeating them all. Syntactic articulation is opposed by Goodman to density, not to disarticulation, the same way density is opposed to finite semantic differentiation, not to infinite in differentiation. These five conditions are fulfilled in various degrees, even being null in some systems. Only systems of notation strictly fulfil all those five conditions.

Goodman synthesizes his proposals convoking the notions of 'analog' and 'digital. ${ }^{27}$ Those notions must not be confused with the notions of 'analogy' and of 'digit', rather being distinguished from one another in terms of 'density' and 'differentiation', even if those terms are not reciprocally opposed. "A symbol scheme is analog if syntactically dense; a system is analog if syntactically and semantically dense." 28 Accordingly, "[a] digital scheme [...] is discontinuous throughout; and in a digital system the characters of such a scheme are one-one correlated with compliance-classes of a similarly discontinuous set." 29 Only a dense system throughout might be an analog system, and only a differentiated system throughout might be a digital system. Consequently, many systems are neither exclusively analog systems, nor exclusively digital systems.

\section{The Arbitrariness of Representation}

Having identified the conditions necessary to achieve a system of notation, Goodman identifies what distinguishes linguistic systems from non-linguistic systems. "Nonlinguistic systems differ from languages, depiction from description, the representational from the verbal, paintings from poems, primarily through lack of differentiation - indeed through density (and consequent total absence of articulation) - of the symbol system." ${ }^{, 30}$ Unlike texts, which, being semantically dense, are legible despite the variations of their graphic forms, a representation is simultaneously syntactically and semantically dense. In painting, not only variations on dimension and color, for instance, demand the recognition of

27. Goodman, Languages of Art: an approach to a theory of symbols, 1976, 159-164.

28. Ibid, 160.

29. Ibid, 161.

30. Ibid, 226. 
different washes, as the differences thus achieved are important to understand what is represented. That is why panting's density or total absence of articulation was underlined.

Therefore if a system of symbols is considered as either linguist or representational according to its degree of density or of absence of articulation, it thus seems necessary to recognize the relativeness of each and every system of symbols' denotative condition and, consequently, the relativeness also of a symbol's denotative value if and when that symbol is considered individually. "Nothing is intrinsically a representation. Status as representation is relative to symbol system. A picture in one system may be a description in another; and whether a denoting symbol is representational depends not upon whether it resembles what it denotes but upon its own relationships to other symbols in a given system. A system is representational only insofar as it is dense; and a symbol is a representation only if it belongs to a system dense throughout or to a dense part of a partially dense system." 31 Therefore, the abandon of the notion of 'kinds of symbols'. A symbol is the symbol it is not because it has a value of it own but because it is part of a particular system of symbols construed from a particular scheme of symbols, thus being distinguished from other symbols according to both the syntactic and the semantic rules current on that system. Only partaking in a given system, symbols might denote an object, being, for example, either a description or a representation of it.

And it is untying the meaning of symbols from any direct relation with the objects being denoted by different systems of symbols, it is untying, hence and once and for all, 'representation' from 'resemblance', that Goodman refuses arbitrariness as an intrinsic quality of linguistic systems and therefore a distinctive one. Goodman does not overlook the distinctions standing between different kinds of systems of denotation. Rather those differences are reiterated. That is why Goodman undertook a comprehensive scrutiny of all those systems' constitutions. But the core of those distinctions should better be sought not in the relation each system of denotation maintains with the objects thus denoted but rather in those systems' either 'articulation' or 'density'.

Arbitrariness permeates each and every system of denotation. "Descriptions are distinguished from depictions not through being more arbitrary but through belonging to articulate rather than to dense schemes; and words are more conventional than pictures only if conventionality is construed in terms of differentiation rather than of artificiality. Nothing here depends upon the internal structure of a symbol; for what describes in some systems may depict in others. Resemblance disappears as a criterion of representation, and structural similarity as a requirement upon notational or any other languages. The often stressed distinction between iconic and other signs becomes transient and trivial; thus does heresy breed iconoclasm." 32

Goodman's understanding about arbitrariness might be better appreciated confronting it with Umberto Eco's one. Goodman and Eco assume signs as being

31. Goodman, Languages of Art: an approach to a theory of symbols, 1976, 226.

32. Ibid, 230-231. 
transitory entities, ${ }^{33}$ thus refusing the notion of 'kinds of signs', but that does not means that they assume as being equally arbitrary all systems of signification. Linguistic and non-linguistic systems are differently evaluated.

Eco's precaution about the so-called iconic signs' arbitrariness is rooted on the iconic codes' 'weakness', which precludes those signs from a stabilized meaning fixing. "The units composing an iconic text are established - if at all - by the context. Out of context these so-called 'signs' are not signs at all, because they are neither coded nor possess any resemblance to anything. Thus insofar as it establishes the coded value of a sign, the iconic text is an act of code-making." 34 Goodman takes that lack of stabilized meaning fixing as the density of those signs. Against linguist signs' arbitrariness, Eco can only counterpoise iconic signs' culturally coded character. And even that character is relative. For Eco iconic systems are not arbitrary because it is not even possible to recognize what they are; it is only possible to recognize them as being culturally coded.

Since arbitrariness has being understood, after Ferdinand de Saussure, ${ }^{35}$ as a distinctive feature of linguistic signs, Eco's precaution about iconic signs might suggest that the later are not considered arbitrary because the former are. The expressions 'naturally linked with' or 'motivated by' ${ }^{36}$ contested by Eco if taken as an explication for ionic signs turn out symmetric of the expressions 'no natural connection with' and 'unmotivated ${ }^{37}$ with which those signs are referred to by Saussure. Iconic signs' evaluation is determined after linguistic signs' one, even because in Eco's own words both take part of a "complex and continuously gradated array of different modes of producing signs and texts." 38 But it is necessary to acknowledge that it is not as linear the impact of linguistic signs on the iconic signs. By ranking codes according either to their 'strength', or to their 'weakness', and thus concluding the arbitrariness pertaining to some of those codes and only the culturally codified character pertaining to the others, Eco performs a verbal approach to the image as one might testify when Eco refers the multiple verbal interpretations called up by a drawing of a horse. "The iconic representation of a horse does not correspond to the word /horse/ but rather to a description (a black horse, standing up, or jumping, etc.), to a mention (this horse is galloping) or to some other different speech act (look what a beautiful horse!)"39 Not only are those two systems differentiated from one another based on how each

33. For Eco, "a sign is not a fixed semiotic entity but rather the meeting ground for independent elements (coming from two different systems of two different planes and meeting on the basis of a coding correlation.)" U. Eco, A Theory of semiotics (Bloomington and London: Indiana University Press, 1976), 49.

34. Eco, A Theory of semiotics, 1976, 216.

35. "The bond between the signifier and the significant is arbitrary. Since I mean by sign the whole that result from the association of signifier with the signified, I can simply say: the linguistic sign is arbitrary. [...] The word arbitrary also calls for a comment. The term should not imply that the choice of the signifier is left entirely to the speaker [...]; I mean that is unmotivated, i.e. arbitrary in that it actually has no natural connection with the signified." F. Saussure, Course in General Linguistics (New York and Chichester, West Sussex: Columbia University Press, 2011), 67, 68-69.

36. Eco, A Theory of semiotics, 1976, 191.

37. Saussure, Course in General Linguistics, 2011, 69.

38. Eco, A Theory of semiotics, 1976, 190.

39. Ibid, 215-216. 
one embraces the same content, as that content's definition is a linguistic one. Symptomatically, iconic signs are considered by Eco as visual texts, and, symptomatically also, Eco fails to realize that no text will ever reach what is revealed by each and every one of those drawings.

Goodman has a distinct approach. Systems of signification are differentiated from one another despite their possible contents. Goodman's inquiry is called "into the nature of languages and into the differences between languages and nonlinguistic symbol systems, as well as into the features that distinguish notational systems from other languages." 40 Therefore, because all those systems are artificial elaborations, Goodman recognizes them all as being arbitrary ones. Eco also assumes that artificiality when recognizing all those systems as being culturally coded. Nevertheless that is not enough to recognize representation as being as arbitrary as language is recognized to be. Eco's representation status is thus unclear. One must wonder how Eco's iconic signs conventional character, even if a volatile one, is made compatible with their non-arbitrariness.

Representation's arbitrariness may at last be confirmed remembering what is being confronted when someone procures to represent something. If a representation and its object are mutually independent entities, otherwise a representation could not be understood autonomously from its object, just like happens, for example, throughout a design process when the object being represented does not have a factual existence of its own, then "the relation that [both] undertake between them is, like with words, arbitrary. [...] Therefore, it is arbitrary the relation between representation and represented." 41

\section{Scale Models, despite Resemblance}

\section{Scale Model as a Dense System of Symbols, after Goodman}

One may now resume architectural scale models' inquiry.

Even if briefly, architectural scale models are addressed by Goodman. For Goodman, "[a] scale model of a campus, with green papier-mâché for grass, pink cardboard for brick, plastic film for glass, etc., is analog with respect to spatial dimensions but digital with respect to material." 42

This scale model is 'analog' for what regards dimensions and shape because it is syntactic and semantically dense - the elements of the scale model and the articulations bounding them are continuously and indefinitely varied, and the scale model will not be able to define its object as a score does, that is, in a one-to-one correspondence. And that same scale model is 'digital' for what regards materials, because it is syntactically discontinuous - its materials are finitely differentiated -, and each one of those materials is associated with its object's material or set of

40. Goodman, Languages of Art: an approach to a theory of symbols, 1976, 130.

41. Translated by the author. Original text: "a relação que mantêm entre si é, como na palavra, arbitrária. [...] Por conseguinte, é arbitrária a relação entre representação $e$ representado.” Janeiro, Origens e Destino da Imagem: para uma fenomenologia da arquitectura imaginada, 2010, 388.

42. Goodman, Languages of Art: an approach to a theory of symbols, 1976, 173. 
materials, being these materials also finitely differentiated - each material or set of materials from that object are not possible to be associated with more than one material at the scale model.

The seemingly 'resemblance' between the materials from the scale model and the materials from the campus - between green papier-mâché and grass, for instance - can only be understood as resulting from the adoption of a 'realistic' standard of representation. Otherwise, if that resemblance would prove necessary to representation, Goodman's commitment on exposing as untenable the need for resemblance in order to accomplish a representation would turn out incomprehensible.

Goodman's scale model matters not because of its features - its 'realism' is far from the abstraction architects tend to privilege -, but rather as a reference to understand scale models' diversity. That campus's scale model corresponds only to a class of scale models. Goodman's example might be putted in perspective with his own arguments. It is possible to consider a scale model based on an articulated scheme of symbols that is still a dense system throughout since it would still be a semantically disjoint one. A scale model built only with a finite amount of ' $L E G O$ ' like modular elements fulfils that requirement. And it is also necessary to acknowledge that a scale model might not be a digital system for what regards its materials if it is built out of a single one. White cardboard scale models testify it.

Rather than identifying under which conditions a scale model may or may not constitute either a partially analog system or a partially digital one, it is more relevant to acknowledge that scale models will not ever constitute a notational system. Unlike a score, it is not possible to warrant neither that a scale model exclusively denotes a given architectural object, nor that only one and the same scale model is elaborated considering both a given architectural object and a given kind of scale models. Scale models do not warrant with architectural objects the kind of invariant conformity relations Goodman identified as necessary to achieve a notational system. Both the abstraction processes of building a scale model and the individual options of who designs and who builds that model prevent it. And "[t]he first semantic requirement upon notational systems is that they be unambiguous." 43

An architectural scale model will always hence be a symbol system if not syntactically at least semantically dense.

\section{Three-Dimensionality, or the Spectre of Resemblance}

Goodman's proposals expose as radically untenable the claim that scale models' representational success is to be found on the resemblance allowed with the architectural objects scale models stand for. And that claim is exposed as a radically untenable one because the links bounding each and every form of denotation to its object were unveiled as strictly artificial ones. Arbitrariness permeates all forms of denotation. No natural links are to be sought there. That is why resemblance was concluded to be a result of representation, not a condition to

43. Goodman, Languages of Art: an approach to a theory of symbols, 1976, 148. 
accomplish it. But the full extension of Goodman's proposals significance continues to be shadowed by everyday use of scale models. Scale models are recognized as coded devices for being a representation, but their representational ability seems to overcome a strictly coded condition. However appealing Goodman's proposals are at a theoretical plane, practice still seems to overrule as being eccentric disputations over scale models' resemblance and proprieties sharing with architectural objects and hence their singular adequacy to represent them, more so if those objects are in the process of being invented. "The domain of inhabitable objects that architecture claims as its own finds its first intimation in the model. The model purports to present architecture, not represent it."44 Too obvious a closeness to be disputed; too useful to be relinquished...

Scale models' coded condition must be readdressed. It is necessary to understand it in all its extension.

Although being consensual, scale models' coded condition is not supported by a uniformly adopted set of codes at least for what regards its expression. "The choices of color (or the lack of it), methods of construction, materials, and level of abstraction are personal." ${ }^{25}$ Nevertheless it is possible to identify same constant options associated with specific purposes. Study scale models might adopt a less strict use of codes, whereas "presentation models portray the complete and fullydetailed composition of an architectural solution and, usually with evidence of its immediate setting, communicate its finality to others. [...] [T] hey take the form of miniature prefigurements." 46 Only the falsehood of an excessive realism will restrain those codes, since realism is commonly perceived by architects as being devoid of a critical comprehension of both reality and representation. "The strength of architects' reaction to realism is usually in direct proportion to their conception of themselves as artists." ${ }^{, 47}$ At the far origin of that reaction is possible to identify Leon Battista Alberti's proposals on 'De Re Aedificatoria. ${ }^{48}$ To be recognized as an intellectual worker and thus prevent his work to be mistaken as an artifice's handwork, Alberti advises architects that rather than over-elaborated "[b]etter then that the models are not accurately finished, refined, and highly decorated, but plain and simple, so that they demonstrate the ingenuity of him who conceived the idea, and not the skill of the one who fabricated the model." $" 49$

Identifying the wide array of codes connected with scale models' expression will prove a difficult if not a non-accomplishable task, and perhaps a rather secondary one. Being associated with a particular understanding of realism, either getting apart from it or getting close to it, and hence associated also with both a

44. C. Hubert, "The Ruins of Representation," in Idea as Model (ed.) K. Frampton and S. Kolbowski (New York: Institute for Architecture and Urban Studies: Rizzoli International Publications, 1981), 17.

45. K. Moon, Modeling Messages the Architect and the Model (New York: The Monacelli Press, 2005), 130.

46. T. Porter and J. Neale, Architectural Supermodels: Physical Design Simulation (Oxford: Architectural Press, 2000), 34.

47. Moon, Modeling Messages the Architect and the Model, 2005, 132.

48. L. Alberti, On the Art of Building in Ten Books (Cambridge, Massachusetts; London, England: The MIT press, 1988).

49. Ibid, 34 . 
given standard system of representation and that system's current validation criteria, it seems far more important to acknowledge those codes as confirming as being culturally afforded - that is, as non 'naturally' granted - the resemblance relations scale models enable with architectural objects. But those codes constitute only a layer of the codification apparatus held by scale models. Scale models' widely recognized comprehensibility turns out admissible that alongside those more diversified and personal codes, or rather underneath them, one must admit the existence of a more uniformly adopted ones. Scale models' comprehensibility could hardly be afforded resting upon just those more idiosyncratic codes. Also this other layer of codes has to be sought. These layers are nevertheless reciprocally inextricable.

As aforementioned, representation might be understood as an encounter between two distinct objects: the one that refers to and the one being referred to, which may or may not be an extant one. But the encounter between a scale model and an architectural object is a particular one for it evolves objects sharing a threedimensional existence. This is the key to understand scale models' coded condition. If, for being a representation, the relation scale models establish with their objects must be addressed as a coded one, due to its three-dimensional existence it is unclear how much that relation depends upon a codification to be established. And if rather not in scale models with a higher scale factor, this is a pertinent issue in large sized scale models which interior might even be experienced and prototypes where "the fine line between a full-sized mock-up and the actual building is crossed." ${ }^{50}$ It is difficult to simply rule out the possibility of the scale model' representational ability being based, at least in part, on a natural relation with architectural objects - that is, a non-coded one - facilitated by the three-dimensionality shared between each other.

Sardo's remarks about the impact of three-dimensionality upon that scale models' ability testify that difficulty. "In the scale model, as the problems of scale reduction do not seem fixed in a stabilized code, it is the permanence of threedimensionality that allows a particularly close link with real architecture. Also the quantitative and qualitative characteristics of reduction are highlighted in a different way: in a large sized architectural scale model it is virtually possible to find each and every point of the real object. An analogical kind of duplication between scale model and architecture that seems to escape, due to its evidence, the need for a codification." 51 At least in these cases, three-dimensionality seemingly exempts architectural scale models from a strictly coded condition.

Underneath expression related codes, seems now to be unveiled no longer the existence of a more uniformly adopted codes as previously pointed out, but rather

50. Porter and Neale, Architectural Supermodels: Physical Design Simulation, 2000, 39.

51. Translated by the author. Original text: "Nel modello, mentre le problematiche della riduzione non appaiono fissate in un codice stabilito, è la permanenza della tridimensionalità che permette di realizzare ugualmente un nesso particolarmente stretto con l'architettura reale. Anche le caratteristiche, quantitative e qualitative, della riduzione si evidenziano in maniera diversa: virtualmente in un modello architettonico di grandi dimensioni è possibile ritrovare ogni punto dell'oggetto reale. Una duplicazione di tipo analogico tra modello e architettura che sembra non soggiacere, nella sua evidenza, alla necessità d'alcuna codifica." N. Sardo, La figurazione plastica dell'architettura: modelli e rappresentazione (Roma: Kappa, 2004), 113-114. 
the presence of links that at the limit dismiss any kind of codification. It is the very notion of representation understood as the result of a coded relation that allows one object to stand for another object that is being challenged.

\section{Three-Dimensionality Reconsidered}

Three-dimensionality status must be addressed at a codifying-plane, even if being a propriety pertaining to objects.

Having no meaning of their own, since they do not signify themselves, objects' meaning must be understood as being attributed by the subject whenever facing or imagining those objects. Objects are thus "meaningful formulations,", as Janeiro points out, accordingly concluding that "the object's qualities are, in fact, subjective projections that qualify the object. [...] It is the subject who deposits on it certain qualifications - those qualities are, hence, of a subjective order and not of an objective order." 53 Recognizing an object as a meaningful formulation implies recognizing it also as a coded entity. A code, as defined by Eco, "[c]onstitutes the rule which correlates elements of expression with elements of content [...]. In order to exist a code it is indispensable that exists a conventional and socialized correspondence." ${ }^{54}$ No meaning can hence be formulated without a code. And not being possible to formulate and to deposit on them, no existence can be ascribed to objects. "Speaking about meaning attribution is speaking about a code that allows setting up that meaning attribution and its consequent decoding. [...] [T] he absence of a code implies the inability to signify." 55 And only being signified do objects acquirer an existence.

The same goes with three-dimensionality. Recognizing an object's threedimensionality is already codifying it. It is inscribing it in an order, a geometrical one for what this case regards, within which a comprehensibility is ascribed to that object. No object is intrinsically a three-dimensional one regardless how overtly reality's evidence might overrule as doubtful this statement. But that is the case. Because each subject lives immersed in a multi-dimensional world, since that world is apprehended along a spatial extension through a temporal extension, recognizing an object as being a three-dimensional one involves an abstraction process that has to be understood as the result of a conceptualization and hence of the existence of a code capable of so cutting out that object from the multidimensional world within which is perceived.

52. Translated by the author. Original text: “formulações significativas." Janeiro, Origens $e$ Destino da Imagem: para uma fenomenologia da arquitectura imaginada, 2010, 16.

53. Translated by the author. Original text: "as qualidades do objecto são, no fundo, projecções subjectivas que qualificam o objecto [...] É o sujeito quem nele deposita certas qualificações - elas são, por isso, de ordem subjectiva e não de ordem objectiva." Ibid, 106.

54. Translated by the author. Original text: "Costituisce la regola di appaiamento di elementi dell'espressione com elementi del contenuto [...] Perché vi sia codice è indispensabili che vi sia corrispondenza convenzionalizzata e socializzata". Eco, Il segno (Milano: ISEDI - Istituto editoriale internazionale, 1976), 143.

55. Translated by the author. Original text: "falar de atribuição de significado, é falar de código que possa instituir essa atribuição de significado, e a sua consequente descodificação. [...] a ausência de código implica a incapacidade de significar". Janeiro, Origens e Destino da Imagem: para uma fenomenologia da arquitectura imaginada, 2010, 40. 
The possibility of an architectural scale model be exempted of a strictly coded condition for the fact of, as the architectural object it stands for, being a threedimensional object as to be ruled out. As for what its three-dimensionality, a scale model must be perceived as any other object pertaining to the world is. But still remain to identify the codes that bond a scale model to an architectural object.

\section{Scale Model's Geometrical Codes}

Architectural drawing's codes allow an insight on scale model's codes. Also architectural drawing must have a set of more pervasive codes underneath more personal ones.

"A drawing type structures a view and thereby the means of representing it. [...] Each type embodies a set of conventions that organizes the information required to make the representation." 56 Orthographic, axonometric and perspective are the most common architectural drawing types. "By "a convention of architectural drawing" I mean the sign - made normally on a two-dimensional surface - that translates into graphic form an aspect (e.g., the plan or elevation) of an architectural design or of an existing building. ${ }^{, 57}$ These are geometrical codes, there resting its importance to the architect's work, being that work permeated, has it always have been, by geometry. Geometry is as much an instrument with which architectural space is manipulated as an order within which the architectural space thus conceived becomes meaningful. Geometry codifies space. "If architecture is the art of the articulation of spaces, then the articulation of spaces codification could be the one Euclid presents in its Geometry." space is inextricable from the object shaping it, it must be extended to that object's articulations the order conferred upon space by geometry. That is why, in Siza's words, the exercise of geometry might be taken as a very definition of architecture - "architecture is to geometrize." ${ }^{, 59}$ Nevertheless, it is more than just practicability that geometry affords to architecture. For being concomitant with the geometrical nature of both architectural space codes' and the codes of the object confining it, architectural drawing code's geometrical nature reflects a certain conceptualization of architecture, of its design, and of representation. "[T] he shaping of architectural ideas chose the obvious path of a close relation with geometry. Geometry would not be visible without Drawing, and Drawing would not be unequivocal without Geometry. The evidence of architecture's ideal-plane could only drive from there. $", 60$

56. I. Fraser and R. Henmi, Envisioning Architecture an Analysis of Drawing (New York: Van Nostrand Reinhold, 1994), 23.

57. J. Ackerman, Origins, imitation, conventions: representation in the visual arts (Cambridge and London: MIT Press, 2002), 294.

58. Translated by the author. Original text: "Se l'architettura è l'arte dell'articolazione degli spazi, allora la codificazione dell'articolazione degli spazi potrebbe essere quella data da Euclide nella sua geometria". Eco, La struttura assente (Milano: Bompiani. 1973), 221.

59. Translated by the author. Original text: "arquitectura é geometrizar." A. Siza, Imaginar a evidência (Lisboa: Edições 70, 2000), 27.

60. Translated by the author. Original text: "a configuração das ideias arquitectónicas escolheu o óbvio percurso da relação estreita com a Geometria. Esta não seria visível sem o 
Extrapolating from what was concluded about architectural drawing, one must have to consider that also architectural scale model codification apparatus' incorporates geometrical codes. As with a drawing, those codes will determine how the architectural object's information being represented must be organized on the elements constituting a scale model, thus enabling certain correspondences between those two objects.

But if geometry codifies not only representation - whereas a drawing or a scale model - but also architectural objects, than, for sharing with those objects the same geometrical order - the one that allows recognizing both as being threedimensional objects -, scale models will also share with architectural objects the geometrical codes with which those objects are comprehended. For a representational purpose, an architectural object is reduced to the same array of shapes a scale model is constituted with. Scale models and architectural objects share between each other the same repertoire of geometrical configurations. That is why a scale model can relate itself to an architectural object without distortion neither of forms nor of proportions. For it requires a transcription from three to two-dimensions, drawings exclude that possibility. In everyday practice, the degree of absence of distortions is relative, as the comparison between a conceptual model or a study scale model with a presentation one proves.

It has to be stressed, for it might be overlooked, that it is a repertoire of geometrical configurations that is shared, not a specific set of geometrical forms, which normally is precluded by the abstraction processes intrinsic to representation, in particular if it implies, as it usually does, a dimensional reduction. Only in a few cases - with large sized walk-in scale models and prototypes, for instance - a coincidence between an architectural object's geometrical forms and a scale model's ones can be considered. And even then that coincidence will prove a relative one, for what is usually represented on a scale model is only a section of an architectural object. But if a scale model replicates an architectural object in all its features - formal and material ones, for instance -, no longer is prompted out the issue of a correspondence between geometrical forms but rather the issue of the limits of the very definition of architectural scale model.

The meaning of sharing a repertoire of geometrical configurations has however to be clarified, for it raises again the spectre of resemblance as the bases for scale model's representational ability. It is at stake the notion of 'sharing'. As aforementioned after Janeiro, the qualities seemingly pertaining to an object are not intrinsic ones but deposited on it by the subject whenever facing it or imagining it. That is why objects ought to be comprehended, again after Janeiro, as 'meaningful formulations. ${ }^{, 1}$ Objects are therefore recognized as coded entities. Outside a code no existence can be considered to an object. There lays the meaning of 'sharing' for what regards the relation between a scale model and an architectural object. Rather than a transfer process, as if an object's set of codes

Desenho, e o Desenho não seria inequívoco sem Geometria. A evidência do plano ideal da arquitectura só poderia daí advir." E. Côrte-Real, O Triunfo da virtude (Lisboa: Livros Horizonte, 2001), 60 .

61. Translated by the author. Original text: "formulações significativas". Janeiro, Origens e Destino da Imagem: para uma fenomenologia da arquitectura imaginada, 2010, 16. 
could simply move to a representation of that object thus profiting from that set of codes, sharing a code implies that the same code is adopted when signifying two otherwise and until then distinct objects. Stating that a scale model and an architectural object share the same geometrical codes has hence to mean that those objects became meaningful formulations - a scale model and an architectural object, for what this case regards - being imposed on them the same geometrical codes.

But scale model's geometrical codes cannot be thoroughly identified without scale being addressed. Practicability demands that architectural scale models usually have an order of magnitude lower than the one of its object. Geometrical codes are hence associated with this demand. Strictly speaking, a scale is an arithmetic coefficient that establishes an equivalence between the dimensions of an object and the dimensions of a representation. But scale manifests itself rather than just as a dimensional equivalences definition and control device. Scale convokes a practice stabilized frame of references that determines how a scale model configuration should be interpreted in order to be recognized as its architectural object configuration. Also scale constitutes a code. The correspondence between a scale model and an architectural object is again confirmed as a culturally coded one. In everyday use, scale determines the information, and not just geometrical one, that should be considered whenever building and observing a scale model, balancing between an inevitable difference from its object and the desire to reach it. But rather than providing resemblances, first and foremost geometrical ones, which, as already remarked, are not likely to happen, scale above all allows to operate with differences and the lack of definition driven from them. And that is a key asset to the work of an architect. "Scale allows the architect a means for climbing towards a definition, developing a balance or medium between a known and an unknown, creating a standard with which to refer and a way of peeling away to reveal that which is unseen., 62

\section{Scale Model's Arbitrariness}

The arbitrariness of the relation between an architectural scale model and an architectural object turns out clear now. Being an architectural scale model and the architectural object it stands for not only distinct from one another but reciprocally independent entities - otherwise neither one nor the other could be autonomously understood and they can so be understood -, and being the relation between those two objects a strictly conventional one - otherwise a scale model could not represent its object since it bears no resemblance with it and carries none of its proprieties -, one must conclude that is also arbitrary, as it is in language, the relation between architectural scale models and architectural objects. The fact that architectural scale models and architectural objects are constituted as equally three-dimensional entities obviates the existence of geometrical codes fulfilling the demands that architectural drawing codes' have to fulfil. A scale model does not require the shuttle between bi-dimensionality and three-dimensionality a drawings

62. A. Smith, Architectural Model as Machine, a New View of Models from Antiquity to the Present Day (Oxford: Architectural Press, 2004), xviii. 
does, but that does not mean that architectural scale models are less coded representations or maybe even non-coded ones as sometimes seems to be considered. Sharing with its objects the same geometrical order does not exempt scale models from codification; determines only that codification's lesser perceptibility. "The physical model has a slightly outsider status. In a physical model there appears to be less code, less representation, less conversion of data into conventional means, and, hence the object - the model - appears to be more real." ${ }^{63}$ Evan if a paradoxical conclusion, architectural scale models do not differ, for what regards the strictly coded condition they establish with their objects, from architectural drawings.

Why then scale models seem so easy to understand to the point of being taken as a non-coded representation? Regardless the reason for that seeming easiness one must nevertheless recognize its roots as stretching beyond the strict limits of the profession. Otherwise presentation models intended to be understood by nonarchitects would prove fruitless. "It may be that the model is not a universal object in terms of legibility, it may instead be deeply culturally determined, but that cultural filter is not a professional one.",64

Being confirmed its strictly coded condition, finding out why scale models seem so easy to understand is no longer about questioning if recognizing a scale model demands mastering a set of codes, but rather how that code mastering is learned. This question becomes more pertinent because rather than what happens with architectural drawing it is difficult to pinpoint as such that mastering of scale models' codes.

Scale models comprehension, particularly the notion of scale, is learned early in life and outside the scope of architectural representation. "[E]very adult has been through an intensive number of years as a child, using miniaturized and scaled objects called toys. Years of learning to control, manipulate and subvert these representations of the adult's world, means that no adult can be fooled by a model. Unlike plans/section/elevations, and statements of design intent, the model is very familiar territory." ${ }^{, 65}$ Children's literature - 'Alice in Wonderland' and 'Gulliver's Travels', for instance - also play a part in learning about scale. But it is growing a self-awareness when comparing himself with the adult that a child internalizes the notion of scale.

An architectural scale model is not a toy, but the differences between them drive not so much from the codes upon which each one is understood, as from how those codes comply with current standards of realism, either getting apart from them - as an architectural scale model usually does -, or getting close to them - as toys often do. The difference between an architectural scale model and toy should rather be sought on the objects each ones represents and the purposes for that representation, than on the mechanisms through which they represent their

63. A. Selenitsch, "Small Real Large," in Homo Faber: Modelling Architecture (ed.) M. Burry, M. Ostwald, P. Downton and A. Mina (Melbourne; Sydney: SIAL and the Melbourne Museum; Archadia Press, 2007), 4.

64. M. Morris, Models: Architecture and the Miniature (West Sussex: Wiley-Academy, 2006), 68.

65. Selenitsch, "Small Real Large,” 2007, 5. 
own objects.

\section{Scale Model and Architectural Object or the Impossibility of a Match}

The lack of any natural resemblance between an architectural scale model and an architectural object being as they are irreconcilably distinct from one another, raises the question of the importance of a scale model to architectural design.

Apparently, a scale model will contribute to the design process' evolution for it allows architects to envision information capable of clarify their still undefined ideas. But one has to realize what information is thus envisioned. No longer being possible to sustain a scale model as a see-through device, because it is no longer being possible to insist on its natural closeness to architectural objects, the information envisioned on a scale model has to be recognized as not being coincident with the information that required it. That is why, one might considered, "[t]here is a danger with any of the possible "tools" that they could falsify our ideas." have to be addressed as standing between the architect and the object he is trying to define. "One conclusion that we might legitimately draw [...] is that the dream of a perfect fit between object and its representation needs to be given up. Doubt and indeterminacy may have to be accepted as the everyday working material of the architect. [...] Theory acts to provoke doubt, but once that doubt has been registered, the challenge of the present is to make do with this corrupt and imperfect material." 67

But no shortcoming should be found there, for no such match between object and its representation should be dreamed about either. In fact, whenever building a scale model, an architect tries to clarify a design intention, subsequently deciding upon its pertinence, either maintaining it, or readjusting it, or even dropping it down. But if that is the sole information considered, if the scale model is interpreted in a restrict manner, the design process, as a research process, will be in risk of getting closed inside itself. Scale model's importance to architectural design must be sought right there, in that missed coincidence between what was intended to be represented and what can be found in a representation. Although that missed coincidence forces thought to confront itself with unforeseen information, that new information and the information already known will be reordered, successively reordered, thus determining the evolution of the design task. "For the normal model to function as part of a chain of process, it can be thought of as lacking." 68 Only when the information already reordered is considered sufficient, that is, only when the balance between what is known and what is unknown about the architectural object being invented is evaluated as being adequate, will the design process be finished. And never that object's definition will be a complete one. No representation will ever fully replicate its object.

Architectural scale models prove important for the invention of architecture

66. Gänshirt, Tools for Ideas an Introduction to Architectural Design, 2007, 81.

67. S. Allen, Practice, Architecture, Technique and Representation (Amsterdam: G+B International, 2000), 45.

68. Morris, Models: Architecture and the Miniature, 2006, 66. 
for being distinct, radically distinct, from the architectural object they are conceived to stand for.

\section{Final Considerations}

This paper was prompted by architectural scale models' singularity as an architectural representation. Scale models have long been trusted by architects to envision their ideas, but still remains largely unacknowledged the nature of the relation they allow with architectural objects. Resemblance arguably enables that relation, the role of scale models in architectural design therefore having to be revaluated.

Goodman's proposals allowed to comprehend architectural scale models' representation ability as a strictly coded one. No resemblance is to be sought between a representation and the object is stands for, for resemblance is no condition for something to stand for something else. Something stands for something else because it is established that way. Standing for is built upon arbitrariness, for being inexistent any natural links with the object being referred to. No resemblance is hence to be sought either between a scale model and an architectural object - not even considering the three-dimensionality shared between each other. Despite the convincing illusion, no complicity is to be found between one and the other. Architectural scale models and architectural objects are radically distinct objects. But rather than a constraint, that distinction proves crucial for architectural design, because by being distinct from its object might a scale model replace it and thus bring order to the architect's thought and only failing to match that object might a scale model contribute to that thought's development.

But no harm will came from still finding out resemblances, for "exact conformity between definition and ordinary practice is never required or to be expected. $" 69$

\section{Acknowledgments}

This work is financed by national funds by FCT - Foundation for Science and Technology under the Project UID/AUR/04026/2013.

\section{Bibliography}

Ackerman, J. Origins, Imitation, Conventions: Representation in the Visual Arts. Cambridge and London: MIT Press, 2002.

Ackoff, R., S. Gupta and J. Minas. Scientific Method. Optimizing Applied Research Decisions. New York \& London: John Wiley \& Sons, 1962.

69. Goodman, Languages of Art: an approach to a theory of symbols, 1976, 220. 
Alberti, L. On the Art of Building in Ten Books. Cambridge, Massachusetts; London, England: The MIT press, 1988.

Allen, S. Practice, Architecture, Technique and Representation. Amsterdam: G+B International, 2000.

Capdevila-Werning, R. Goodman for Architects. London and New York: Routledge, 2014.

Churchman, C., R. Ackoff and E. Arnoff. Introduction to Operations Research. New York \& London: John Wiley \& Sons, 1957.

Côrte-Real, E. O Triunfo da virtude [The Triumph of the Virtue.] Lisboa: Livros Horizonte, 2001.

Echenique, M. "Models: a discussion." In Urban Space and Structures. Edited by L. Martin, and L. March. Cambridge" Cambridge University Press, 1975, 164-175.

Eco, U. La struttura assente [The Absente Structure.] Milano: Bompiani. 1973. Il segno [The Sign.] Milano: ISEDI - Istituto editoriale internazionale, 1976. A Theory of Semiotics. Bloomington and London: Indiana University Press, 1976.

Fraser, I. and R. Henmi. Envisioning Architecture an Analysis of Drawing. New York: Van Nostrand Reinhold, 1994.

Gänshirt, C. Tools for Ideas an Introduction to Architectural Design. Basel Boston Berlin: Birkhäuser Verlag AG, 2007.

Goodman, N. Languages of Art: An Approach to a Theory of Symbols. Indianapolis and Cambridge: Hackett Publishing Company, Inc., 1976.

Hubert, C. "The Ruins of Representation." In Idea as Model. Edited by K. Frampton and S. Kolbowski. New York: Institute for Architecture and Urban Studies: Rizzoli International Publications, 1981, 17-27.

Janeiro, P. Origens e Destino da Imagem: para uma fenomenologia da arquitectura imaginada [Origins and Destiny of the Image: towards a phenomenology of the imagined architecture.] Lisboa: Chiado Editora. 2010.

Moon, K. Modeling Messages the Architect and the Model. New York: The Monacelli Press, 2005.

Morris, M. Models: Architecture and the Miniature. West Sussex: Wiley-Academy, 2006.

Porter, T. and J. Neale. Architectural Supermodels: Physical Design Simulation. Oxford: Architectural Press, 2000.

Sardo, N. La figurazione plastica dell'architettura: modelli e rappresentazione. [The Plastic figuration of Architecture: models and representation.] Roma: Kappa, 2004.

Saussure, F. Course in General Linguistics. New York and Chichester, West Sussex: Columbia University Press, 2011.

Selenitsch, A. "Small Real Large." In Homo Faber: Modelling Architecture. Edited by M. Burry, M. Ostwald, P. Downton and A. Mina. Melbourne; Sydney: SIAL and the Melbourne Museum; Archadia Press, 2007, 4-9.

Siza, A. Imaginar a evidência [To imagine the Evidence.] Lisboa: Edições 70, 2000.

Smith, A. Architectural Model as Machine, a New View of Models from Antiquity to the Present Day. Oxford: Architectural Press, 2004. 
